\title{
Seasonal Variability in Aerosol Microphysical Properties over Selected Rural, Urban and Maritime Sites in Kenya
}

\author{
Geoffrey W. Khamala, Jared O. Odhiambo, John W. Makokha \\ Department of Science, Technology and Engineering, Kibabii University, Bungoma, Kenya \\ Email:khamalawanjala@gmail.com
}

How to cite this paper: Khamala, G.W., Odhiambo, J.O. and Makokha, J.W. (2018) Seasonal Variability in Aerosol Microphysical Properties over Selected Rural, Urban and Maritime Sites in Kenya. Open Access Library Journal, 5: e4821.

https://doi.org/10.4236/oalib.1104821

Received: August 1, 2018

Accepted: October 21, 2018

Published: October 24, 2018

Copyright $\odot 2018$ by authors and Open Access Library Inc.

This work is licensed under the Creative Commons Attribution International License (CC BY 4.0).

http://creativecommons.org/licenses/by/4.0/

\begin{abstract}
Atmospheric aerosols are posing a great threat to the already stressed climate with the effects being felt more on African continent. Their presence and interaction with the clouds contribute to the strongest uncertainty in aerosol characteristics and Earth's energy budget hence; calling for a long term assessment to be done. The present study analyses long term spatiotemporal microphysical aerosol characteristics (namely: effective radius $\left(r_{\text {eff }}\right)$ and surface-area concentration), using AErosolROboticNETwork (AERONET) framework over Kenyan urban atmosphere (Nairobi- $1^{\circ} \mathrm{S}, 36^{\circ} \mathrm{E}$ ), rural atmosphere (ICIPE-Mbita- $0^{\circ} \mathrm{S}, 34^{\circ} \mathrm{E}$ ) and maritime atmosphere (CRPSM-Malindi-2 ${ }^{\circ} \mathrm{S}$, $40^{\circ} \mathrm{E}$ ). AERONET framework was used due to its availability over the selected sites; it is also located in sites that provided contrasting aerosols type, source and characteristics and due to its synergism with other frameworks. The findings indicated a spatial and temporal variability in microphysical properties over CRPSM-Malindi, Nairobi and ICIPE-Mbita. CRPSM-Malindi is dominated with coarse aerosols in all seasons while Nairobi with coarse mode in the DJF and MAM seasons. ICIPE-Mbita is on the other hand dominated with fine aerosols in all season. In terms of size distribution, the three AERONET sites displayed a bimodal distribution inflecting at $0.44 \mu \mathrm{m}$ and fine mode radius of $0.15 \mu \mathrm{m}$ while CRPSM-Malindi recorded a coarse mode of $3.86 \mu \mathrm{m}$ and Nairobi and ICIPE-Mbita with $5.06 \mu \mathrm{m}$. The coarse aerosols have a higher concentration than the fine aerosols in all AERONET sites because of aerosol coagulation and dominance of certain type of aerosols that are coarse in nature.
\end{abstract}

\section{Subject Areas}

Atmospheric Sciences, Environmental Sciences 


\section{Keywords}

Aerosol Characterization, Kenyan Atmosphere, Microphysical Properties, Spatial and Temporal Characteristics

\section{Introduction}

Aerosols are tiny (micro and submicron) sized particles (solid or liquid) that are suspended in the atmosphere [1]. They are injected in atmosphere from both natural and anthropogenic sources [2] and distributed through turbulence and regional circulation; thus their concentration and distribution are highly variable in space and time [3].

Aerosol variability depends on factors such as dominant anthropogenic emissions, natural loading and atmospheric conditions [4]. Their presence in the atmosphere directly modulates the Earth's radiative budget by scattering and absorption of the incoming solar radiation yielding a cooling and warming effect respectively [4] [5]. They also indirectly modulate the radiative budget of the earth by modifying the properties of the cloud condensation nuclei (CNN) which aid in the formation of cloud droplets [5] [6] [7]. The atmospheric aerosols have been on an increasing trend especially in the third world countries such as Kenya due to growing populace, rapid urbanization and changes in land use, increased vehicular emissions, and increased industrialization within and adjacent to, urban areas [8] [9].

The presence and variability of atmospheric aerosols have strongly contributed to greater uncertainties in aerosol optical, microphysical and chemical characteristics [10]. Despite plenty of ground, remotely sensed data uncertainty has still continued to exist on how aerosols microphysical characteristics (effective radius and size distribution) contribute to environmental effects therefore need to characterize them thus forming the basis of this study.

\section{Materials and Methods}

\subsection{Study Sites}

The study was undertaken in the region described in detail by Makokha [9]. These sites were chosen because they provided contrasting aerosol microphysical characteristics and presence of AERONET frame work hence Figure 1 shows the sites of study in Kenya.

\subsection{Instrumentation}

The study uses the AErosolROboticNETwork (AERONET) to analyze the spatial and temporal variability of both effective radius and size distribution. This program [11] is a federation of ground remote sensing aerosol networks established by NASA (National Aeronautics and Space Administration). The program provides a long term, continuous and readily accessible public domain database of 


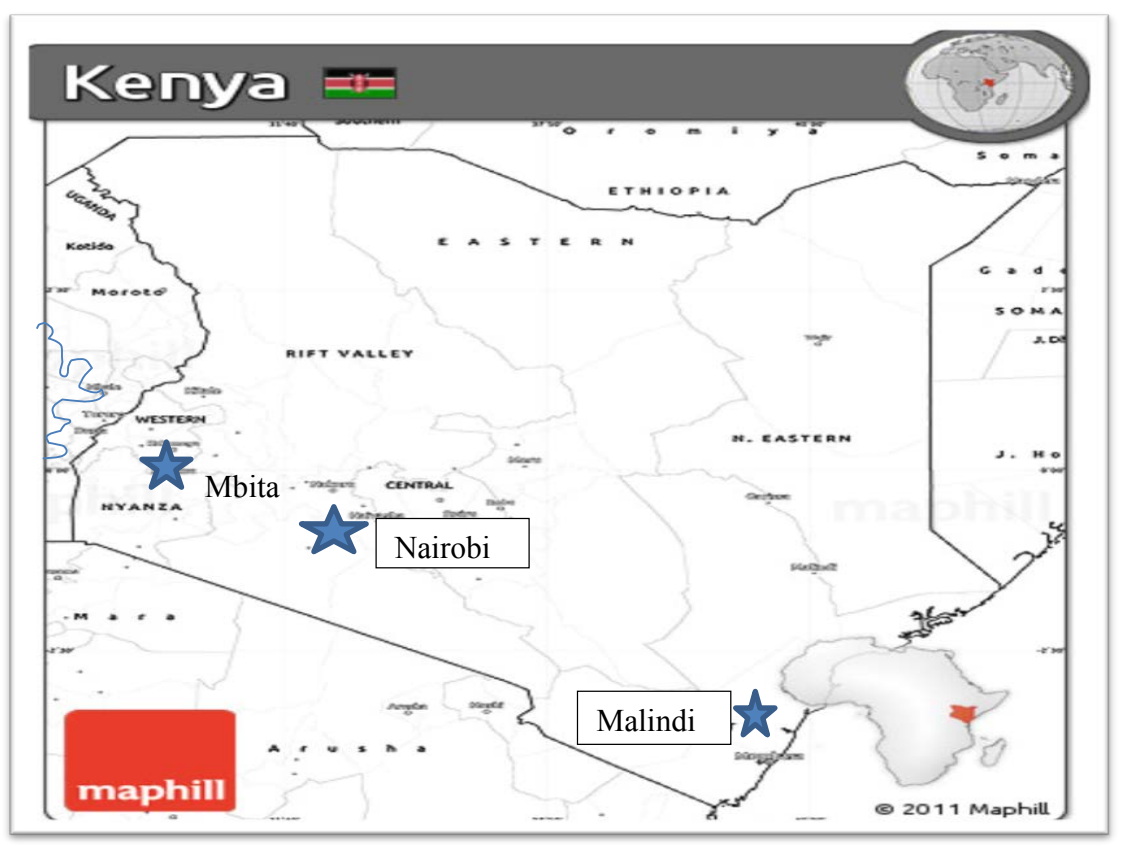

Figure 1. AERONET sites in Kenya. Source: http://www.maphill.com. Date: 04.08.2017.

aerosol optical, microphysical and radiative properties for aerosol research and characterization, validation of satellite retrievals and synergism with other database.

\subsection{Derivation of Microphysical Properties.}

Derivation of climate models, visibility and how human health is affected through aerosol characterization requires a better understanding of effective radius $\left(r_{\text {eff }}\right)$ and surface-area concentration (size distribution). The sensitivity of climate change, visibility and human health caused by natural and anthropogenic variations of the above-listed microphysical properties characterizes the impact of the atmospheric aerosol on climate change; visibility and human health hence need for aerosol characterization.

Effective radius $\left(r_{e f f}\right)$ is the area weighted mean radius of the aerosol particles. It determines the size of the aerosol particles. The derivation of $\left(r_{\text {eff }}\right)$ is given by Equation (1) and has been described in details by Dubovik [12].

$$
r_{e f f}=\frac{\int_{0}^{\infty} r^{3} \frac{\mathrm{d} N(r)}{\mathrm{d} \ln r} \mathrm{~d} \ln r}{\int_{0}^{\infty} r^{2} \frac{\mathrm{d} N(r)}{\mathrm{d} \ln r} \mathrm{~d} \ln r}
$$

where $r$ is the particle radius, $\mathrm{d} N(r)$ particle distribution. The particles and droplets in aerosols in Equation (1) collide with one another undergoing coalescence leading to change in the aerosol particle size distribution. This increases aerosol diameter as total number of particles decreases, hence size distribution of the particle volume $\frac{\mathrm{d} V(r)}{\mathrm{d} \ln r}$ relates with the particle number by the formula 
$[12]$

$$
\frac{\mathrm{d} V(r)}{\mathrm{d} \ln r}=V(r) \frac{\mathrm{d} N(r)}{\mathrm{d} \ln r}=\frac{4}{3} \pi r^{3} \frac{\mathrm{d} N(r)}{\mathrm{d} \ln r}
$$

The data for the daily averages for both effective radius and size distribution were downloaded from the AERONET inversions ( $V 3$ ) over three AERONET sites in WordPad which was then imported to excel for further manipulation and analysis. These data were regrouped in respective seasons i.e. DJF, MAM, JJA and SON by first deleting the field values and then finding the averages from which, line graphs were plotted for respective seasons throughout the period of study. The variability of seasonal plots over same site were analyzed with time hence a temporal erraticism of aerosol microphysical properties while on the other hand, a spatial variability was achieved by comparing DJF, MAM, JJA and SON of one AERONET site with the seasons from other AERONET sites.

\section{Results and Discussions}

\subsection{Spatial and Temporal Characteristics of Aerosol Microphysical Properties}

AERONET data of level 1.5 from the three AERONET stations (obtained from January 2004 to December 2017) were considered in this study to investigate both the spatial and temporal variation of $r_{\text {eff }}$ and size distribution over Kenya.

\subsection{Spatial and Temporal Characteristics of Effective Radius.}

$r_{\text {eff }}$ refers to mean radius of the aerosol particles. It determines the size of aerosol particles hence can be characterized as fine mode (particle size $<0.6 \mu \mathrm{m}$ ) or coarse (particle size $>0.6 \mu \mathrm{m}$ ) mode aerosols [13] [14]. To start with is the analysis of the $r_{\text {eff }}$ over CRPSM-Malindi considering the DJF, MAM, JJA and SON respectively.

From Figure 2(a), it was noted that $r_{\text {eff }}$ during DJF was varying with time. In 2009, $r_{\text {eff }}$ was noted to range between $0.35 \mu \mathrm{m}$ and $1.13 \mu \mathrm{m}$ thus an indicator that aerosol sizes vary with time. Higher (lower) radius is a signature of larger (smaller) sized aerosols. Equally, there was a temporal variability in $r_{\text {eff }}$ of aerosol in 2009 season with DJF posting an average of $0.68 \mu \mathrm{m}$ while in 2010 and 2011; the same season posted an average of $0.73 \mu \mathrm{m}$ and $0.72 \mu \mathrm{m}$ with a range of $0.32-1.00 \mu \mathrm{m}$ and $0.48-1.48 \mu \mathrm{m}$ respectively. A greater variability was noted in 2013 , with the lowest and highest radius of $0.41 \mu \mathrm{m}$ and $1.81 \mu \mathrm{m}$ respectively followed with highest variability in 2017 season registering a range of $0.42-3.17$ $\mu \mathrm{m}$ and mean of $0.99 \mu \mathrm{m}$, an indicator of coarse mode aerosols [14] [15]. The reduced amount of PR during this local dry season, the sink of marine and Arabian desert aerosols were ascertained to be the main causes of variability [8] [9].

Additionally, Figure 2(b) indicates variability of $r_{\text {eff }}$ in MAM season over CRPSM-Malindi with time. The 2008 season, recorded an average of $0.70 \mu \mathrm{m}$ with a range of $0.30-1.58 \mu \mathrm{m}$. The variability slightly increased in the 2011 season recording an average and range of $0.63 \mu \mathrm{m}$ and $0.39-1.83 \mu \mathrm{m}$ respectively 

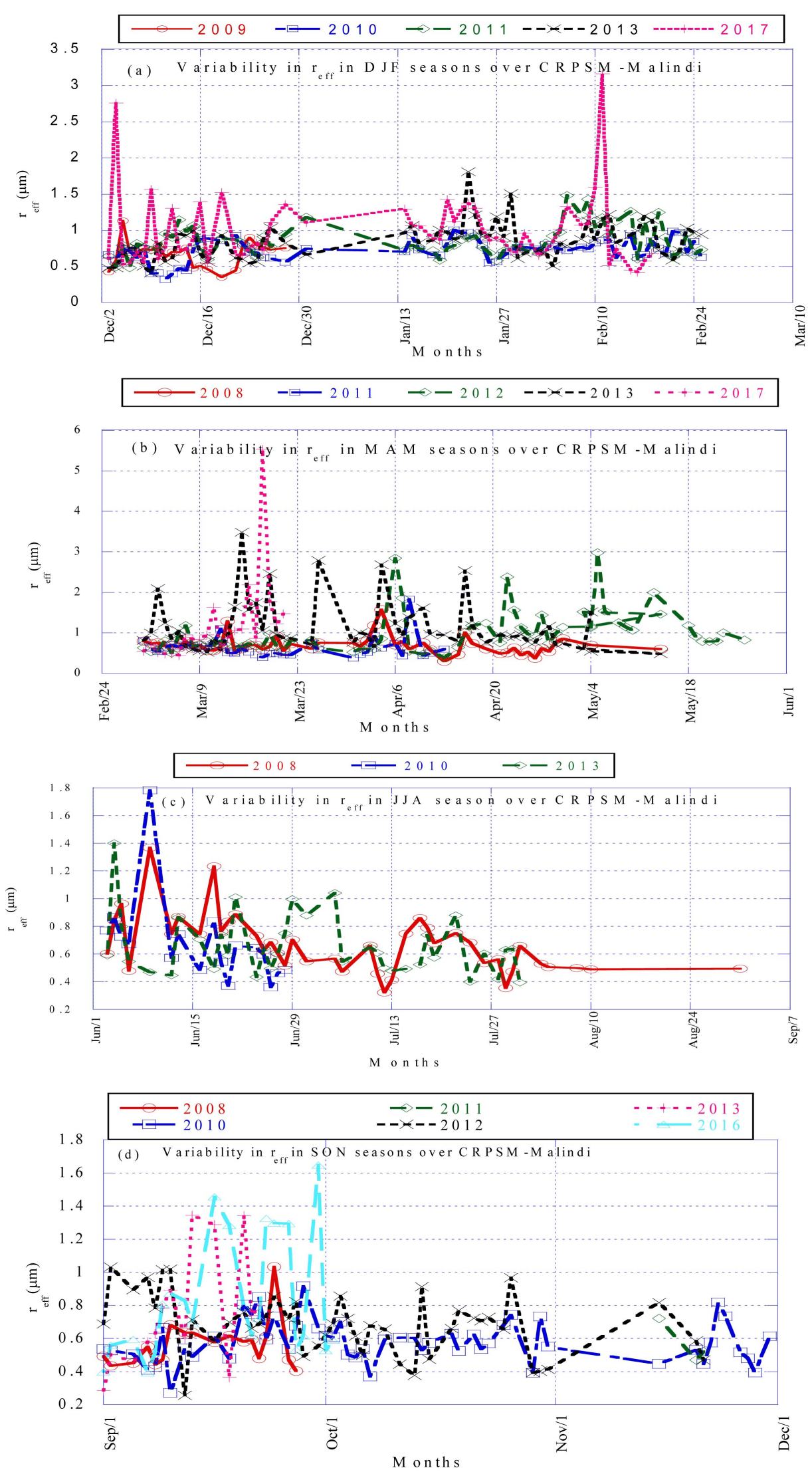

Figure 2. Variability in effective radius over CRPSM-Malindi during study period. 
but 2012 season recorded the largest radius as $2.98 \mu \mathrm{m}$ with smallest as $0.38 \mu \mathrm{m}$ and average of $0.99 \mu \mathrm{m}$. a range and average of $0.48-3.49 \mu \mathrm{m}$ and $1.14 \mu \mathrm{m}$ respectively were recorded in 2013 MAM and the greatest variability during this season was recorded in 2017, during which the highest average of $1.20 \mu \mathrm{m}$ and range of 0.45 - 5.43 were recorded. The variability in volume distribution was favored by increased amount of PR in MAM thus increased aerosols wash down [9] [14].

Also, as noted in Figure 2(c), it was observed that $r_{\text {eff }}$ in JJA was varying with time that was attributed to different aerosol source and type. It was observed that during 2008 season, an average $r_{\text {eff }}$ of $0.66 \mu \mathrm{m}$ and range of 0.32 $1.37 \mu \mathrm{m}$ was recorded. The variability was additionally experienced in 2010 posting a range and average of $0.36-1.78 \mu \mathrm{m}$ and $0.68 \mu \mathrm{m}$ respectively. The variation in 2013 season appeared to reduce slightly recording a range of $0.39-1.40$ $\mu \mathrm{m}$. The averages recorded are a signature of coarse aerosols dominating the region [12] [13] Aerosols from different sources such as flowering crops attributed to the variability and enhanced aerosols in JJA over the three AERONET sites [15].

Lastly, during 2008 SON season as indicated in Figure 2(d) $r_{\text {eff }}$ was noted to vary with time with an average of $0.56 \mu \mathrm{m}$ being recorded and range of 0.40 $1.03 \mu \mathrm{m}$, an indicator that it was majorly dominated with fine mode aerosols. The study equally indicates that 2010 and 2011 were majorly dominated with the fine mode aerosols registering averages of $0.58 \mu \mathrm{m}$ and $0.57 \mu \mathrm{m}$, and ranges of $0.27-0.92 \mu \mathrm{m}$ and $0.47-0.72 \mu \mathrm{m}$ respectively. The variability increased in subsequent years with the mode changing to majorly coarse mode with highest variability noted in 2016 posting a range of $0.39-1.65 \mu \mathrm{m}$ and average of $0.83 \mu \mathrm{m}$ greater than $0.6 \mu \mathrm{m}$ suggested by Dubovik [12] thus dominated by coarse aerosols. The study attributed the variability to the fluctuation in the amount of the precipitation during SON seasons [9].

Equally, $r_{\text {eff }}$ over Nairobi AERONET site during the period of study was also analyzed and the findings represented as in Figure 3.

During the 2006 and 2009 DJF seasons, the $r_{\text {eff }}$ was noted to vary with time as indicated in Figure 3(a). The 2006 DJF season was noted to register an average of $0.72 \mu \mathrm{m}$ with a greater variability of $0.30-1.46 \mu \mathrm{m}$ being experienced while the 2009 DJF recorded a lower variability and average radius of $0.44-0.62$ $\mu \mathrm{m}$ and $0.53 \mu \mathrm{m}$ respectively. Equally, the MAM season registered variability in $r_{\text {eff }}$ with time as indicated in Figure 3(b). The 2006 season recorded an average $r_{\text {eff }}$ and range of $0.52 \mu \mathrm{m}$ and $0.35-0.69 \mu \mathrm{m}$ respectively and a signature of fine mode aerosols while during 2009 season, it recorded an average of $0.84 \mu \mathrm{m}$ an indicator of coarse mode aerosols. The enhanced temporal variability over this region was attributed by many sources of atmospheric aerosols such as industrial emissions, fuel burning and aerosols transported to the region by both monsoon winds [9].

Additionally, the analysis of the $r_{\text {eff }}$ over ICIPE-Mbita was done and the findings represented as in Figure 4. 

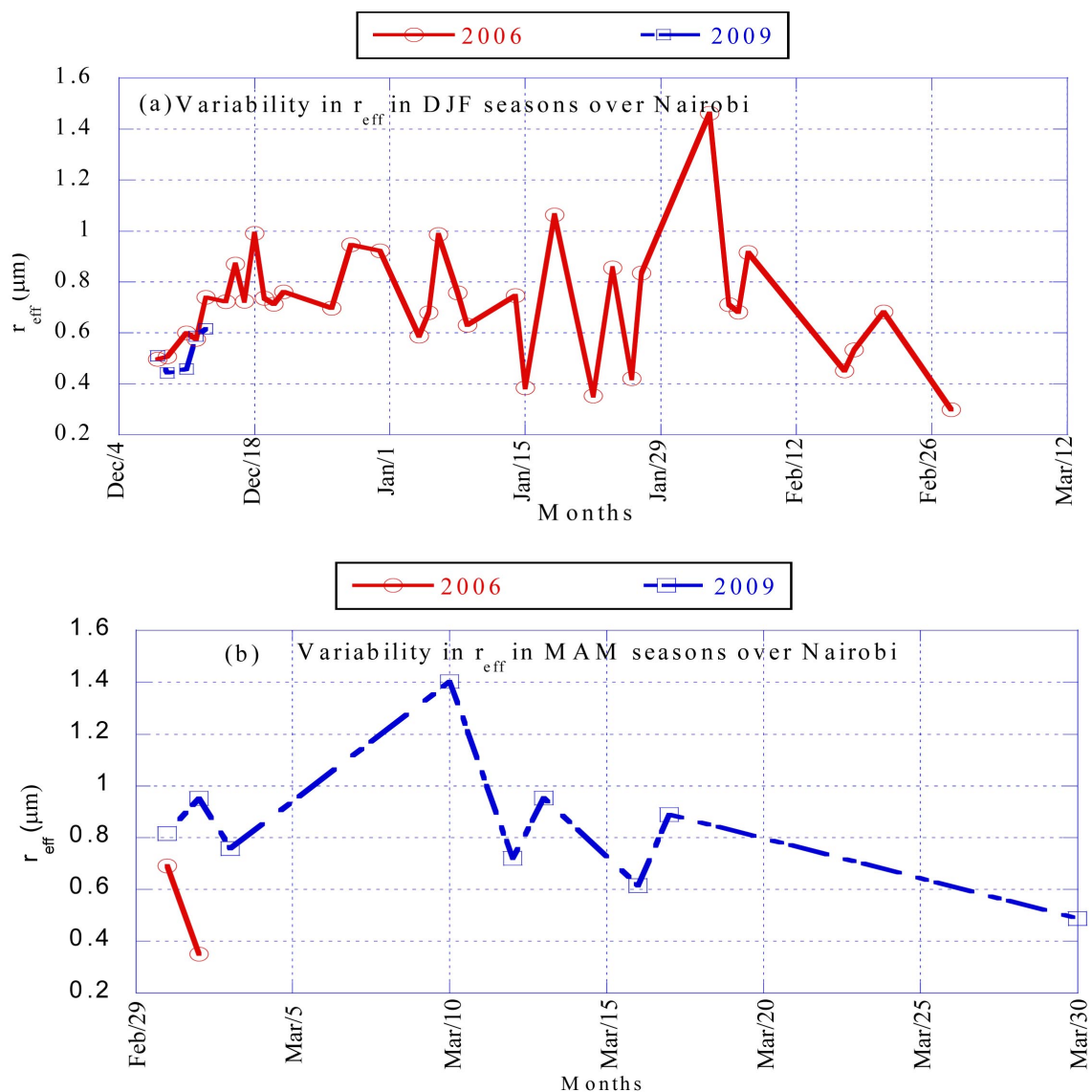

Figure 3. Variability in effective radius over Nairobi during the period of study.

Temporal characteristic of $r_{\text {eff }}$ was equally analyzed over ICIPE-Mbita and it can be noted from Figure 4(a) that the average $r_{\text {eff }}$ recorded in DJF of 2007 indicated dominance of fine mode aerosols since it posted an average of $0.42 \mu \mathrm{m}$ and range of $0.19-0.84 \mu \mathrm{m}$. A slight variability was equally noted in the 2008 and 2009 DJF season with range of $0.34-0.72 \mu \mathrm{m}$ and $0.30-0.73 \mu \mathrm{m}$ respectively and both having an average of $0.51 \mu \mathrm{m}$. This was followed by a greater variability in 2010 with a range of $0.29-2.58$ and 0.63 as the average radius; a signature of dominance by coarse mode [14]. The 2011 season recorded the least variability of $0.37-0.41 \mu \mathrm{m}$ and the least average $0.39 \mu \mathrm{m}$. The highest average of $1.08 \mu \mathrm{m}$ and greatest variability of $0.47-3.36 \mu \mathrm{m}$ was note in 2013 and it was followed with smaller variability of $0.33-0.98 \mu \mathrm{m}$ and bigger average radius of $0.62 \mu \mathrm{m}$ in 2015 . During this local dry season, the variability was attributable to increased biomass burning, vehicular emission and increased construction around the region [14] [15].

Furthermore, during local wet MAM season as indicated in Figure 4(b) the study noted that $r_{\text {eff }}$ was varying with time due to different types of atmospheric aerosols [14]. During 2007 season, the site recorded an average of $0.45 \mu \mathrm{m}$ and a stretch of $0.21-1.29 \mu \mathrm{m}$ while in 2008 , it noted an average of $0.81 \mu \mathrm{m}$ a signature of coarse mode and a range of $0.41-1.86 \mu \mathrm{m}$. But 2011 season noted a 

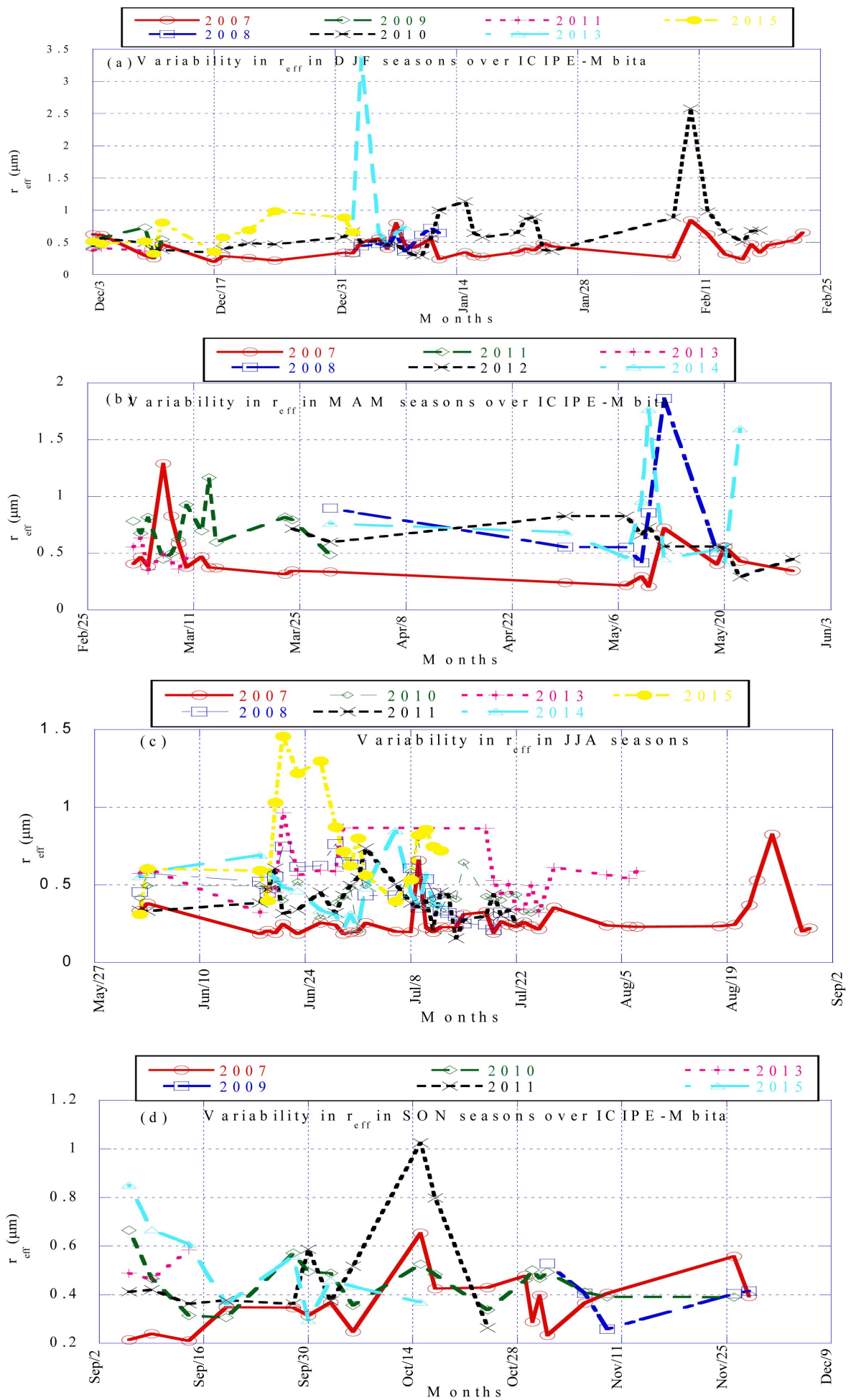

Figure 4. Variability in effective radius over ICIPE-Mbita during the period of study.

slight decrease in average radius and range to $0.72 \mu \mathrm{m}$ and $0.45-1.17 \mu \mathrm{m}$ respectively. The aerosol $r_{e f f}$ further reduced in 2012 and ranged between the radius of $0.29-0.83 \mu \mathrm{m}$ and mean of $0.62 \mu \mathrm{m}$. The lowest variability was noted in the year 2013 posting a stretch of values of $0.35-0.64 \mu \mathrm{m}$ and mean of $0.47 \mu \mathrm{m}$ 
but in 2014 season, the variability greatly increased to a range of $0.41-1.77 \mu \mathrm{m}$ while mean of $0.85 \mu \mathrm{m}$.

In the JJA season as indicated in Figure 4(c), a temporal variability was equally noted with 2007 season recording an average and range in radius of 0.27 $\mu \mathrm{m}$ and $0.18 \mu \mathrm{m}$ to $0.83 \mu \mathrm{m}$, an indication that the site is dominated with fine mode. 2008 and 2010 season both registered an average of $0.48 \mu \mathrm{m}$ and $0.43 \mu \mathrm{m}$ with the radius spanning $0.21-0.76 \mu \mathrm{m}$ and $0.20-0.80 \mu \mathrm{m}$ respectively. In addition, the 2011 and 2013 seasons recorded an equally lower variability in $r_{\text {eff }}$ with the range of $0.16-0.74 \mu \mathrm{m}$ and $0.32-0.96 \mu \mathrm{m}$ and mean $r_{\text {eff }}$ of $0.39 \mu \mathrm{m}$ and $0.55 \mu \mathrm{m}$. A further lower variability in the radius was noted in $2014 \mathrm{span}-$ ning $0.21-0.85 \mu \mathrm{m}$ while registering an average radius of $0.46 \mu \mathrm{m}$. The highest variability in $r_{\text {eff }}$ was noted in 2015 season with the values spanning the value of $0.31-1.46 \mu \mathrm{m}$ and the average radius of $0.77 \mu \mathrm{m}$. From the findings the study noted that ICIPE-Mbita is majorly dominated with fine mode aerosols during this season. Aerosols from different sources such as flowering crops and aerosols from Lake Victoria attributed to the variability in JJA over the three AERONET sites [14].

A temporal variability over ICIPE-Mbita during the SON season as indicated in Figure 4(d) displayed $r_{\text {eff }}$ variability with time an indication of different aerosol types. The 2007 season recorded a mean radius of $0.36 \mu \mathrm{m}$ and range of $0.21-0.65 \mu \mathrm{m}$ while 2009 season noted a slightly higher radius of $0.41 \mu \mathrm{m}$ and lower range of $0.26-0.53 \mu \mathrm{m}$. The site again noted a slight increase in radius and range during 2010 season, posting values of $0.45 \mu \mathrm{m}$ and $0.31-0.67 \mu \mathrm{m}$ in that order. The variability and mean radius hit the highest values during 2011 season with the radius stretching between $0.26-1.03 \mu \mathrm{m}$ and mean radius of $0.50 \mu \mathrm{m}$. The 2013 and 2015 seasons reached same mean radius of $0.51 \mu \mathrm{m}$ and range of $0.47-0.58 \mu \mathrm{m}$ and $0.29-0.85 \mu \mathrm{m}$ respectively.

Spatial variability was similarly noted over the three AERONET sites as indicated in Figures 2-4. CRPSM-Malindi recorded average of $r_{\text {eff }}>0.6 \mu \mathrm{m}$ in all the seasons an indicator that it is majorly dominated with the coarse mode aerosols while Nairobi recorded average of $0.63 \mu \mathrm{m}$ and $0.68 \mu \mathrm{m}$ in the DJF and MAM respectively a signature of large sized aerosols in these seasons. But ICIPE-Mbita recorded the average $r_{e f f}<0.6 \mu \mathrm{m}$ in all seasons thus a pointer that it is majorly dominated with the fine mode aerosols [12] [14].

\subsection{Spatial and Temporal Characteristics of Surface Area Concentration}

Surface area concentration (Particle size distribution) over AERONET sites dictates the fluctuation in the aerosol radius with time. To start with are the variations in the size distribution over CRPSM-Malindi seasons from 2008 to 2017. It is noted from Figures 5(a)-(e) that there is a temporal variability displayed in a bimodal distribution of aerosol particle size with an inflection at $0.44 \mu \mathrm{m}$ in all seasons and high concentration in coarse aerosols than fine aerosols. The sizes in 

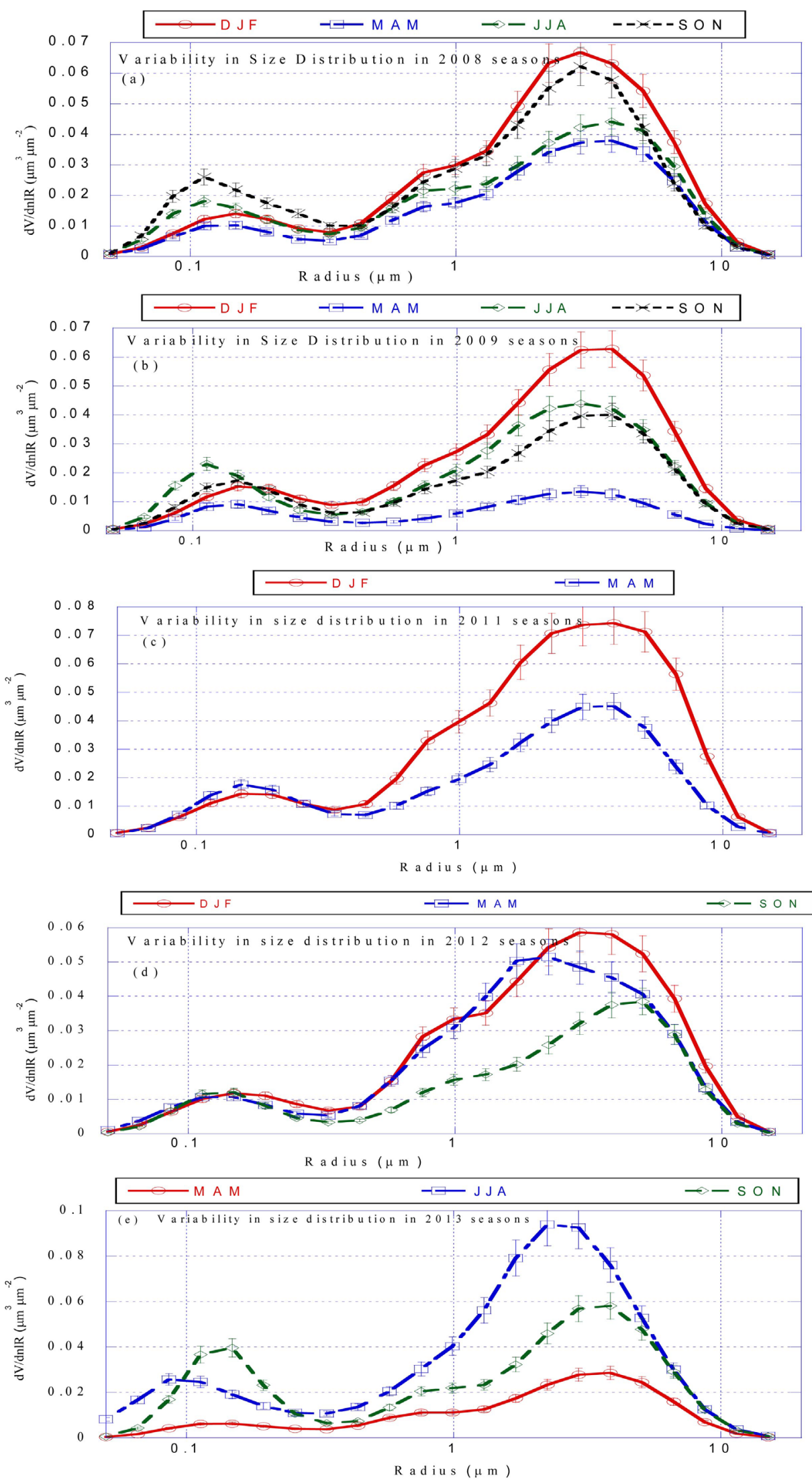

Figure 5. Variability in size distribution over CRPSM-Malindi during study period. 
DJF, MAM JJA and SON seasons of 2008 as noted in Figure 5(a) oscillated with time with highest concentration of fine aerosols at $0.15 \mu \mathrm{m}, 0.15 \mu \mathrm{m}, 0.09 \mu \mathrm{m}$ and $0.11 \mu \mathrm{m}$ respectively while coarse mode concentrated at $2.94 \mu \mathrm{m}, 3.86 \mu \mathrm{m}$, $3.86 \mu \mathrm{m}$ and $2.94 \mu \mathrm{m}$ respectively. Moreover, the variability was displaying a bimodal distribution of aerosols with large sized particles being higher than small sized particles and indication of mixed aerosol [14] [16] [17].

Equally, from Figure 5(b), its noted to display bimodal distribution of aerosols with fine mode radius of $0.15 \mu \mathrm{m}$ in all seasons while the coarse mode radius in DJF, MAM and JJA seasons of $2.94 \mu \mathrm{m}$ and coarse mode radius of 3.86 in SON season. Again the temporal characteristics during the 2011 seasons displayed in Figure 3(c) \& Figure 4(c) indicate that DJF and MAM season both had same fine mode radius and coarse mode radius of $0.15 \mu \mathrm{m}$ and $3.86 \mu \mathrm{m}$ respectively [12] [14].

The 2012 seasons equally indicated a variation of aerosol size with time. The DJF and MAM both recorded fine aerosol and coarse aerosol modes as $0.15 \mu \mathrm{m}$ and $2.94 \mu \mathrm{m}$ respectively while SON season of the same year posted fine mode radius of $0.15 \mu \mathrm{m}$ and coarse mode radius of $5.06 \mu \mathrm{m}$. The 2013 seasons noted a great variability of aerosol sizes distribution with MAM and SON seasons both posting fine mode radius of $0.15 \mu \mathrm{m}$ and coarse mode radius of $3.86 \mu \mathrm{m}$. Additionally, JJA noted much smaller fine mode radius and coarse mode radius of $0.09 \mu \mathrm{m}$ and $2.24 \mu \mathrm{m}$ respectively.

Away from size distribution over CRPSM-Malindi, the study also investigated the same property over Nairobi during the same period whose findings were represented as the sunisoidal waves in Figure 6. The size of distribution of aerosols was noted to have a greater variability over Nairobi as indicated in with the curve inflecting at $0.44 \mu \mathrm{m}$ in all the seasons. The study noted that the distribution displayed a bimodal kind of distribution with the larger particle being more than the fine particle. As indicated in Figure 6(a), the 2006 DJF, MAM and JJA seasons posted a fine mode radius of $0.15 \mu \mathrm{m}$ with a greater variability in the coarse mode radius. DJF posted the highest coarse mode radius of $6.64 \mu \mathrm{m}$ followed by MAM with radius of $5.06 \mu \mathrm{m}$ while JJA recorded lower coarse mode radius of $3.86 \mu \mathrm{m}$. Also, SON season recorded a lower fine mode radius of 0.11 $\mu \mathrm{m}$ with coarse mode radius of $3.86 \mu \mathrm{m}$. The variability in fine mode and coarse mode over this region indicates that aerosol size distribution varies temporally due to coagulation and changes in the aerosol type dominating the atmosphere [14] [16].

Although only two seasons were recorded during the 2007 the study noted a significant seasonal variation as it may be observed from Figure 6(b). The large sized particles were more than the small sized particles and larger sized aerosols dominated the atmosphere during the DJF and MAM seasons both posting a fine mode aerosol radius of $0.15 \mu \mathrm{m}$ and coarse mode aerosol radius of 0.506 $\mu \mathrm{m}$. Also, the 2008 seasons displayed a bimodal distribution of aerosols with DJF posting the lowest fine mode radius of $0.09 \mu \mathrm{m}$, while MAM and JJA recorded 

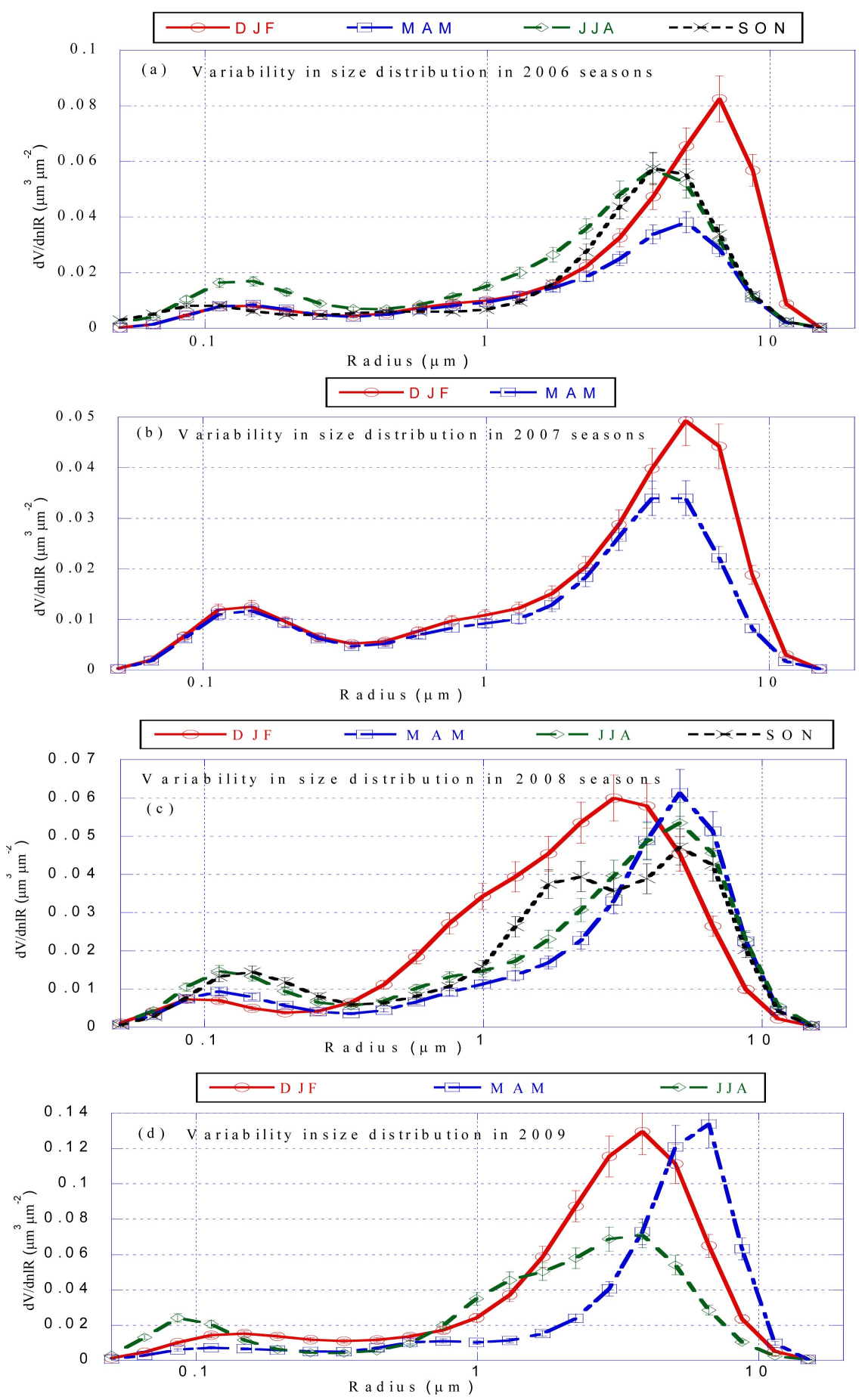

Figure 6. Variability in size distribution over Nairobi during study period.

aerosol fine mode of $0.11 \mu \mathrm{m}$ and SON a higher value of $0.15 \mu \mathrm{m}$. A greater variability was noted in the coarse mode aerosol radius with $2.94 \mu \mathrm{m}$ as the lowest radius in DJF and $5.06 \mu \mathrm{m}$ as the highest coarse mode radius in the MAM, JJA and SON seasons [12] [14].

The study equally investigated size distribution over ICIPE-Mbita during the same period and the findings represented as in Figure 7. 

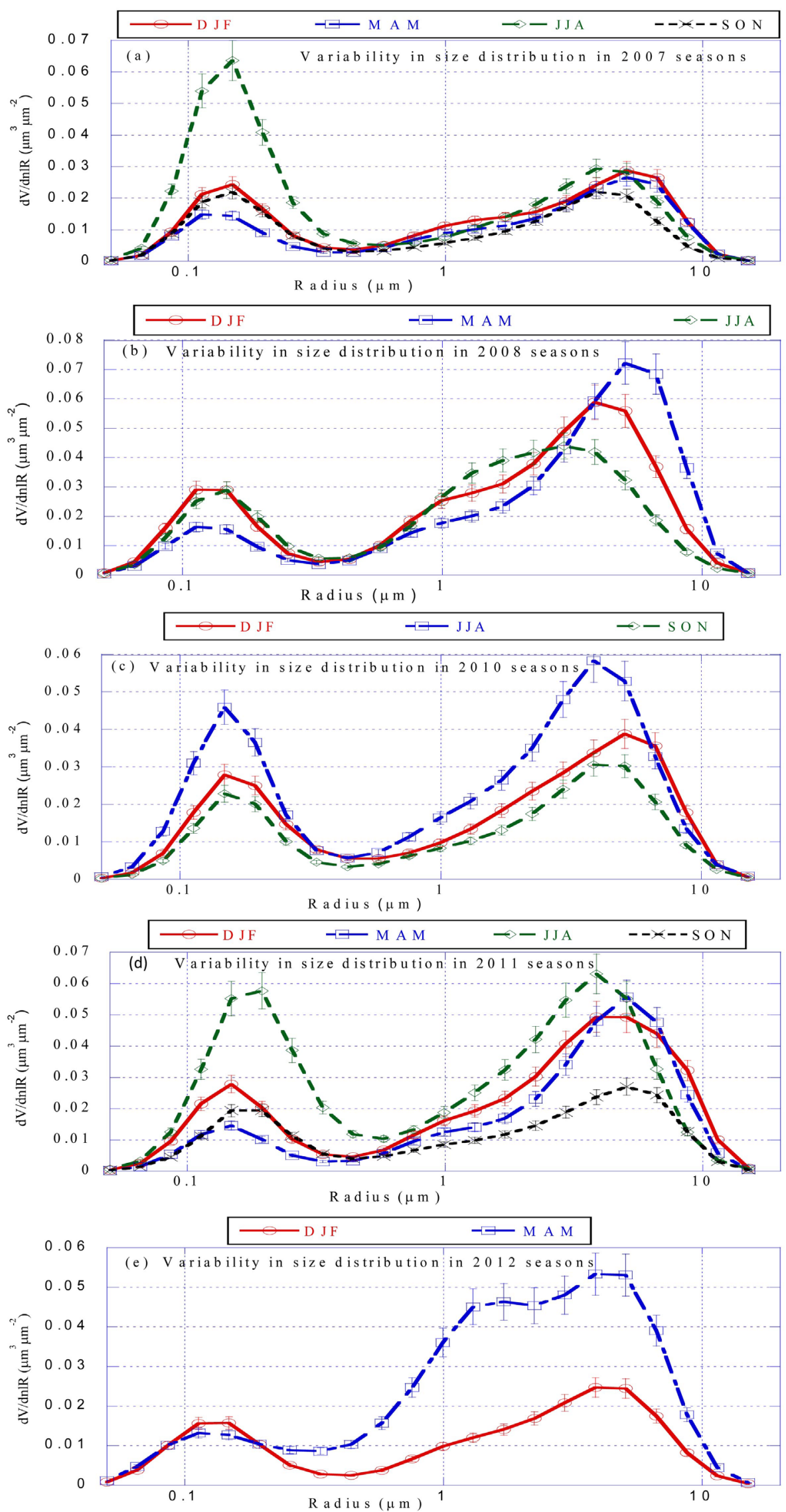

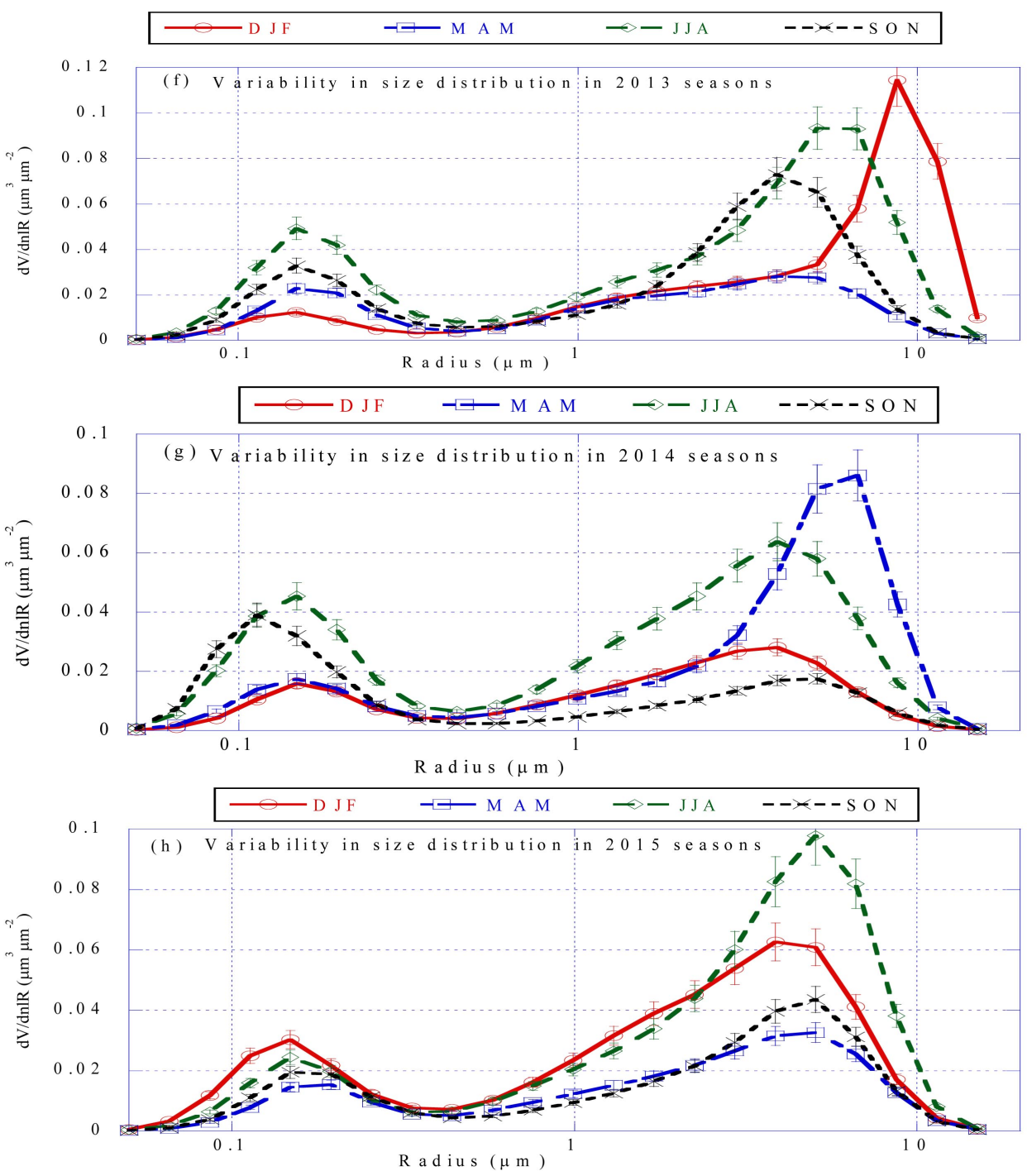

Figure 7. Variability in size distribution over ICIPE-Mbita during period of study.

It is noted from Figure 7 that there is a temporal variability that displays a bimodal distribution of aerosol particle size over ICIPE-Mbita. In 2007 as noted in Figure 7(a), the fine mode aerosol radius recorded in DJF, JJA and SON was $0.15 \mu \mathrm{m}$ while MAM recorded a lower mode of $0.11 \mu \mathrm{m}$. Also, the coarse mode radius was note to vary with time with DJF and MAM seasons recording the mode as $5.06 \mu \mathrm{m}$ while JJA and SON seasons with $3.86 \mu \mathrm{m}$. Equally, Figure 7(b) displayed bimodal distribution of aerosols recording fine mode radius of 0.11 $\mu \mathrm{m}$ in DJF and MAM while JJA recorded a values of $0.15 \mu \mathrm{m}$. Lower coarse mode radius of $3.86 \mu \mathrm{m}$ was recorded in DJF while higher mode of $5.06 \mu \mathrm{m}$ in MAM and JJA.

Temporal characteristics may also be noted in 2010 seasons as displayed in Figure $7(\mathrm{c})$. Its indicated that a fine mode radius of $0.15 \mu \mathrm{m}$ is posted in all seasons while coarse mode radius of $5.06 \mu \mathrm{m}$ is realized in DJF while $3.86 \mu \mathrm{m}$ in JJA and SON. The 2011 seasons equally indicated a variation of aerosol size distribu- 
tion with time as indicated in Figure 7(d). DJF and MAM realized a fine mode radius of 0.15 and a coarse mode radius of $3.86 \mu \mathrm{m}$ and $5.06 \mu \mathrm{m}$ respectively while JJA and SON both registered a higher fine mode radius of $0.19 \mu \mathrm{m}$ and coarse mode radius of $3.86 \mu \mathrm{m}$ and $5.06 \mu \mathrm{m}$ respectively. While in $2012 \mathrm{DJF}$ and MAM seasons, aerosols size distribution indicated bimodal distribution with fine mode radius as $0.15 \mu \mathrm{m}$ and $0.11 \mu \mathrm{m}$ respectively with both seasons posting coarse mode radius of $3.86 \mu \mathrm{m}$ [14].

Additionally, the 2013 seasons displayed an interseasonal variation with a bimodal distribution between the fine and coarse mode aerosols, as it may be noted from Figure 7(e). Its depicted that the all seasons had the same fine mode radius of $0.15 \mu \mathrm{m}$ but posted a variation in the coarse mode radius with DJF and JJA registering radius of $5.06 \mu \mathrm{m}$ while MAM and SON with radius of $3.86 \mu \mathrm{m}$. This is an indicator that JJA and DJF are dominated with coarse particles while MAM and SON are dominated with fine particles [14]. The average of the 2014 seasons as indicated in Figure 7(f) displayed a variation in the aerosol sizes distribution as DJF, MAM and JJA posted a fine mode radius of $0.15 \mu \mathrm{m}$, while SON with radius of $0.11 \mu \mathrm{m}$. A greater variability in size distribution was noted with coarse mode radius ranging between $3.86 \mu \mathrm{m}$ in the DJF and JJA to $6.64 \mu \mathrm{m}$ in MAM. Lastly, 2015 seasons as indicated in Figure 7(g) equally implied a variation in aerosol size distribution with time. DJF, JJA and SON recorded fine mode radius of $0.15 \mu \mathrm{m}$ while MAM posted a higher fine mode radius of 0.19 $\mu \mathrm{m}$. In addition, the coarse mode radius was noted to vary with DJF recording $3.86 \mu \mathrm{m}$ and MAM, JJA and SON all recorded mode of $5.06 \mu \mathrm{m}$.

Additionally, spatial analysis of size distribution over three AERONET sites was done and noted that CRPSM-Malindi had an average fine and coarse modes of $0.15 \mu \mathrm{m}$ and $3.48 \mu \mathrm{m}$ while Nairobi and ICIPE-Mbita both had the average modes of $0.15 \mu \mathrm{m}$ and $5.06 \mu \mathrm{m}$. The greatest variability in the size distribution was note over Nairobi while the lowest variability was over CRPSM-Malindi. The study attributed the low variability over coastal region to the ever present sea salt in the region [5] [8] [18].

\section{Conclusion and Recommendation}

\section{Conclusion}

The $r_{\text {eff }}$ and size distribution were varying both spatially and temporally over the three AERONET sites. CRPSM-Malindi and Nairobi had the higher average in $r_{\text {eff }}>0.6 \mu \mathrm{m}$ whereas ICIPE-Mbita had lower averages of $0.6<r_{\text {eff }}$, a signature that CRPSM-Malindi is dominated with large sized particles in all seasons while Nairobi is with coarse mode aerosols in DJF and MAM and ICIPE-Mbita is dominated with fine aerosols in all seasons. The three AERONET sites displayed a bimodal distribution of aerosols with coarse aerosols having a higher concentration than the fine aerosols due to aerosol coagulation. CRPSM-Malindi experiences low variability in size distribution due to constantly being dominated with sea salt from Indian Ocean. 


\section{Acknowledgements}

The authors wish to acknowledge National Aeronautics and Space Administration (NASA) through PI Holben B. for establishing and maintaining AErosol RObotic NETwork (AERONET) frame work over Kenya. Additionally, we thank the AERONET online data system developed and maintained by the NASA Goddard Earth Science Distributed Active Archive (NASA GES DISC) from which inversion 2 and level 1.5 data was obtained.

\section{Conflicts of Interest}

The author declares no conflicts of interest regarding the publication of this paper.

\section{References}

[1] Balarabe, M., Abdullah, K. and Nawawi, M. (2016) Seasonal Variations of Aerosol Optical Properties and Identification of Different Aerosol Types Based on AERONET Data over Sub-Sahara West-Africa. Atmospheric and Climate Sciences, 6, 13-28. https://doi.org/10.4236/acs.2016.61002

[2] Seinfeld, J.H. and Pandis, S.N. (2012) Atmospheric Chemistry and Physics: From Air Pollution to Climate Change. John Willey and Sons, Inc., New York, 1326 p.

[3] Mkoma, S.L. and Mjemah, I.C. (2011) Influence of Meteorology on Ambient Air Quality in Morogoro, Tanzania. International Journal of Environmental Sciences, 1, 1107-1115.

[4] Charlson, R.J., Schwartz, S.E., Hales, J.M., Cess, R.D., Coakley Jr., J.A., Hansen, J.E. and Hoffman, D.J. (1992) Climate Forcing by Anthropogenic Aerosols. Science, 255, 423-430. https://doi.org/10.1126/science.255.5043.423

[5] Makokha, J.W., Kimani, J.N. and Angeyo, H.K. (2012) Estimation of Radiative Forcing Due to Aerosols over Selected Sites in Kenya. Journal of Meteorological Research, 6, 3-13.

[6] Lyamani, H., Valenzuela, A., Perez-Ramirez, D., Toledano, C., Granados-Muñoz, M.J., Olmo, F.J. and Alados-Arboledas, L. (2015) Aerosol Properties over the Western Mediterranean Basin: Temporal and Spatial Variability. Atmospheric Chemistry and Physics, 15, 2473-2486. https://doi.org/10.5194/acp-15-2473-2015

[7] Makokha, J.W., Odhiambo, J.O. and Shem, J.G. (2018) Long Term Assessment of Aerosol Radiative Forcing over Selected Sites of East Africa. Journal of Geoscience and Environment Protection, 6, 22-34. https://doi.org/10.4236/gep.2018.64002

[8] Ngaina, J.N., Mutai, B.K., Ininda, J.M. and Muthama, J.N. (2014) Monitoring Spatial-Temporal Variability of Aerosols over Kenya. Ethiopian Journal of Environmental Studies and Management, 7, 244-252. https://doi.org/10.4314/ejesm.v7i3.3

[9] Makokha, J.W., Odhiambo, J.O. and Godfrey, J.S. (2017) Trend Analysis of Aerosol Optical and Angstrom Exponent Anomaly over East Africa. Atmospheric and Climate Sciences, 7, 588-603. https://doi.org/10.4236/acs.2017.74043

[10] Houghton, J.T., Ding, Y., Griggs, D.J., Noguer, M., Van der Linden, P.J., Dac, X., Maskell, K. and Johnson: Intergovernmental Panel on Climate Change (IPCC) (2013) Climate Change 2013; The Specific Basis. Contribution of Working Group 1 for the Fifth Assessment Report.

[11] Holben, B.N., Eck, T.F., Slutsker, I., Tanre, D., Buis, J.P., Setzer, A., Vermote, E., 
Reagan, J.A., Kaufman, Y.J., Nakajima, T., Lavenu, F., Jankowiak, I. and Smirnov, A. (1998) AERONET-A Federated Instrument Network and Data Archive for Aerosol Characterization. Remote Sensing of Environment, 66, 1-16. https://doi.org/10.1016/S0034-4257(98)00031-5

[12] Dubovik, O., Videen, G., Yatskiv, Y. and Mish-Chenko, M. (2006) Optimization of Numerical Inversion in Photopolarimetric Remote Sensing. In: Videen, G., Yatskiv, Y. and Mishchenko, M., Eds., Photopolarimetry in Remote Sensing, Kluwer Academic Publishers, Dordrecht, 65-106.

[13] Dubovik, O. and King, M.D. (2002) Flexible Inversion Algorithm for Retrieval of Aerosol Optical Properties from Sun and Sky Radiance Measurements. Journal of Geophysical Research, 105, 20673-20696. https://doi.org/10.1029/2000JD900282

[14] Boiyo, R.K., Kumar, R. and Zhao, T. (2018) Optical, Microphysical and Radiative Properties of Aerosols over a Tropical Rural Site in Kenya, East Africa: Source Identification, Modification and Aerosol Type Discrimination. Journal Atmospheric Environment, 177, 234-252. https://doi.org/10.1016/j.atmosenv.2018.01.018

[15] Makokha, J.W., Angeyo, H.K. and Muthama, J.N. (2017b) Aerosol Optical Depth and Precipitation Rate Projections over East Africa Utilizing Self Organizing Map The International Journal of Science \& Technoledge, 5, 166-175.

[16] Ashwin, P., Pulkit, M., Suman, S.L. and Ravi, K.S. (2011) AERONET DATA ANALYSIS ASL720: Project Report.

[17] Shupeng, W., Li, F., Xingying, Z. and Weihe, W. (2015) Retrieval of Aerosol Properties for Fine/Coarse Mode Aerosol Mixtures over Beijing from PARASOL Measurements. Remote Sensing, 7, 9311-9324. https://doi.org/10.3390/rs70709311

[18] Juma, S.G., Nzioka, J.M. and Bethwel, K.M. (2015) Simulation of Radiative Forcing Due to Aerosols over Some Counties in Kenya. International Journal of Medicine, and Sciences. 